\title{
Capturing Genetic Variability and Identification of Promising Drought-Tolerant Lines in Exotic Landrace Derived Population Under Reproductive Drought Stress in Rice
}

OPEN ACCESS

Edited by:

Bhumi Nath Tripathi,

Indira Gandhi National Tribal

University, India

Reviewed by: Joong Hyoun Chin,

Sejong University, South Korea Krishnamurthy S. L., Central Soil Salinity Research Institute (ICAR), India

*Correspondence:

Paresh Chandra Kole pckole@gmail.com Arvind Kumar

arvind.kumar@cgiar.org

Specialty section: This article was submitted to

Plant Abiotic Stress,

a section of the journal

Frontiers in Plant Science

Received: 14 November 2021

Accepted: 11 January 2022

Published: 14 February 2022

Citation:

Venkateshwarlu C, Kole PC,

Paul PJ, Singh AK, Singh VK and Kumar A (2022) Capturing Genetic

Variability and Identification of Promising Drought-Tolerant Lines in Exotic Landrace Derived Population Under Reproductive Drought Stress in Rice. Front. Plant Sci. 13:814774.

doi: 10.3389/fpls.2022.814774

\section{Challa Venkateshwarlu1,2, Paresh Chandra Kole2*, Pronob J. Paul', Arun Kumar Singh', Vikas Kumar Singh ${ }^{1}$ and Arvind Kumar ${ }^{1,3 *}$}

${ }^{1}$ International Rice Research Institute (IRRI), South Asia Hub, Patancheru, India, ${ }^{2}$ Institute of Agriculture, Viswa Bharati University, Sriniketan, India, ${ }^{3}$ International Crop Research Institute for the Semi-Arid Crops (ICRISAT), Patancheru, India

Drought is one of the most predominant abiotic stresses in this century, leading to a drastic reduction in the yield of rainfed rice ecosystems. Breeding of drought-resilient rice varieties is very much in demand for sustainable rice production in drought-prone rainfed ecology. An experiment was designed under irrigated non-stress and drought-stress situations involving an exotic drought-tolerant landrace (Chao Khaw) and a high-yielding aromatic rice cultivar (Kasturi), and an $\mathrm{F}_{2: 4}$ derived population of 156 breeding lines was developed at IRRI South Asia Hub, Hyderabad. The objective of the study was to assess the genetic variability, drought tolerance behavior, and identify promising breeding lines for different rice ecologies and drought breeding programs. Restricted maximum likelihood (REML) analysis using the mixed model approach revealed a considerable genetic variation in the population for yield and yield contributing traits in non-stress and drought-stress conditions. We observed very high heritability for all the selected traits under stress 2015 WS (73.8\% to 85.3\%) and 2016 WS (72.4\% to 93.5\%) and non-stress 2015 WS (68.2\% To 92.9\%) and 2016 WS (61.4\% to 92.6\%) environments, indicating possible selection for grain yield under drought stress and non-stress with the same precision level. None of the secondary traits except harvest index and biomass included in our study showed a positive association with grain yield, indicating indirect selection's ineffectiveness in improving yield under drought. A total of 48 promising breeding lines were found to have a better yield than donor Chao Khaw (up to 38\% advantage) and popular drought-tolerant cultivars Shabhagidhan (up to 48\% advantage) in stress conditions and recommended for rainfed upland ecology, 34 breeding lines under the well-watered condition suited for rainfed lowland ecology. Overall, the study found 21 common breeding lines that showed their superiority in non-stress and under drought stress situations, fitting best in rainfed lowland ecology with occasional drought occurrence. The large genetic variation found in this population can be exploited further to develop a few forward breeding high-yielding lines with better drought tolerance ability and used as drought donors in drought breeding programs.

Keywords: drought-tolerant, abiotic stress, Chao Khaw, Kasturi, rainfed ecology, genetic variability 


\section{INTRODUCTION}

Climate change is not a myth but a fact, which becomes a great threat to society due to its potential to intensify extreme events such as drought around the globe. Increased global temperatures and frequent changes in monsoon primarily cause the occasional droughts and floods, more common in many rice-growing areas in South and Southeast Asia.

Rice is the most widely consumed staple food as a cereal grain, is one of the most water-intensive crops, and grows about in the 25.12 million hectares area in irrigated conditions and 42.75 million hectares in lowland conditions in India. Moreover, rice consumes about $80 \%$ of irrigated freshwater resources worldwide (Wu et al., 2017). However, freshwater becomes increasingly scarce due to climate change and other factors such as rapid industrialization, urbanization, and groundwater mining (Bates et al., 2008; Xiong et al., 2010; Yan et al., 2015). According to a report, 15-20 million hectares of irrigated rice will face water scarcity by 2025 (Wu et al., 2017). Thus, it is a great challenge for the farmers to produce rice with limited water to meet the growing population's food demand.

On the other hand, rainfed lowland ecology covers 33\% of the rice area globally but yields only $19 \%$ of total global production (Rao et al., 2017). This comparatively low contribution toward total rice production of rainfed lowland ecology suffers from low productivity ranging from 1.5 to 2.5 tonnes (Rao et al., 2017). The unpredicted and frequent drought due to a disturbed monsoon or a long spell between two rainfall seasons causes the low productivity in this ecology. In Asia alone, about 34 million hectares of rainfed lowland and 8 million hectares of rainfed upland rice experience drought stress of varying intensities at different crop stages almost every year (Wopereis et al., 1996; Huke et al., 1997).

Many rice varieties grown in rainfed ecology are primarily developed for irrigated conditions and are preferred due to their high-yielding potential and better grain quality. These varieties are high yielding during the favorable season but perform poorly during the occurrence of occasional drought. Since the rainfed rice ecology is highly variable, breeding for drought-prone climate needs varieties that combine high-yielding potential with good drought tolerance (Zeigler and Puckridge, 1995). It is also imperative to breed better drought-equipped rice varieties with increased yield under drought conditions to encourage sustainable rice production in rainfed and irrigated ecosystems (Zeigler and Puckridge, 1995). A valuable and practical breeding approach for drought breeding and drought-tolerant rice varieties could lead to food security under growing food demands, limited resources, and unpredicted climatic variability.

The evolution of rice cultivars in drought-prone rainfed areas has allowed the development of a large number of droughttolerant landraces which can withstand drought to many extents. Many of these landraces have also been known to possess deep roots up to $70 \mathrm{~cm}$ below the soil surface. Greater root length density at depth has also been reported in droughttolerant landraces such as Dular, Azucena, and Rayada compared with high-yielding drought-susceptible varieties such as IR64 (Henry et al., 2011). However, most landraces have low-yielding potential, low tillering, tall plant height, and poor grain and eating quality. Despite being known to possess drought tolerance, very few of them have been systematically characterized for the trait. Previous decades have used many landraces to develop droughttolerant cultivars and identify QTLs, for example, Basmati 370, PSBRc 80, Aus 257, Dhagad Deshi, Kali Aus Nagina 22, Aus Bak Tulsi, Dular (Wu et al., 2017).

Most traditional drought-tolerant donors are not used directly in breeding programs because of the linkage drag of several undesirable traits they possess. Hence, identifying and introgression of the genes or QTLs from them to existing elite varieties is the primary step for developing new generation drought-tolerant rice cultivars for rainfed lowland areas.

In the past, many drought-tolerant lines were developed by successful crosses between a drought-tolerant donor and a high-yielding drought-sensitive cultivar (Atlin, 2003). This study adopted the same method to attempt and produce drought-tolerant lines involving a drought-tolerant landrace collected from Laos and high-yielding aromatic rice with drought sensitivity. This population's assessment would also help to study rice's drought-tolerant behavior relating to exotic landrace as a donor. Besides, we were also interested in creating novel genetic variability for drought tolerance in rice to identify novel QTLs or genes for drought in further study.

\section{MATERIALS AND METHODS}

\section{Experimental Details}

Experiments were conducted at the International Rice Research Institute (IRRI), South Asia Hub (IRRI-SAH), ICRISAT Campus, Hyderabad in 2015 WS (wet season/rainy season) and 2016 WS. The experimental plots are situated $\left(78^{\circ} 16^{\prime}\right.$ longitude, $17^{\circ} 32^{\prime}$ latitude, and $540 \mathrm{~m}$ above sea level). The soil type of the conducted experimental plots was clay loam in texture. The non-stress experiments were sown during June and drought stress experiments were sown in July in 2015 WS and 2016 WS. To avoid the monsoon rain and maintain the drought cycle imposition, the sowings of the drought-stress experiment were delayed for one month from the non-stress experiment to get the severe stress cycles throughout the crop cycle. This drought imposition and drought screening method have been highly successful in the earlier study (Kumar et al., 2009).

\section{Plant Materials}

Kasturi (RP 2144-108-5-3-2), long slender, improved aromatic variety for the irrigated lowland ecosystem variety, which has developed by selection from the cross-Basmati 370/CRR 88-171-5 at Indian Institute of Rice Research (IIRR), Rajendra Nagar, Hyderabad, was released for commercial cultivation in the year 1994. This variety is semidwarf in stature $(95 \mathrm{~cm})$, matures at 135 to 140 days, and yields about 30 to 35 quintals under the wellwatered situation with an optimum nutrient application, which shows sensitivity during the reproductive stage drought situation. On the other hand, the donor parent, Chao Khaw, is a long bold Laos landrace, collected by the International Rice Research Institute germplasm collection and identified as a promising 
drought-tolerant genotype with blast-resistant having low grain quality traits, semitall in stature $(110 \mathrm{~cm})$ with medium duration (120 to 125 days) (IRRI unpublished data).

\section{Development of Population}

The population was developed by crossing between Kasturi and Chao Khaw in the dry season (postrainy) of 2014, and $34 \mathrm{~F}_{1}$ seeds were generated. True single plants were harvested in 2014 WS, and $200 \mathrm{~F}_{2}$ individual plants were harvested in the dry season of 2015. Finally, in our study, 156 breeding lines in the $\mathrm{F}_{2: 3}$ and $\mathrm{F}_{2: 4}$ generations were included for screening for two main rice seasons in two conditions. IR 64, a high-yielding but drought-sensitive variety, and Sahabagidhan, a drought-tolerant variety, were planted along with the population in non-stress and reproductive stage drought-stress conditions.

\section{Phenotyping for Grain Yield Under Reproductive Stage Drought-Stress and Non-stress Conditions}

The phenotypic evaluation of the $\mathrm{F}_{2: 3}$ and $\mathrm{F}_{2: 4}$ population was conducted under well-watered and reproductive stage drought conditions. The field selected for the study was upland in topography with good drainage and loamy clay soil. Seeds were sown in a nursery bed and transplanted in the main field after 25 days of sowing under non-stress (well water condition) and reproductive stage drought-stress condition. Under non-stress and reproductive stage drought-stress conditions, each family was planted in two-row of $2 \mathrm{~m}$ with $20 \mathrm{~cm} \times 15 \mathrm{~cm}$ spacing. The experiments were laid out with an augmented RCBD design with checks and parents repeated five times, and a standard package of practices was followed to raise the good crop. The total rainfall received during the crop cycle was $421.8 \mathrm{~mm}$ in $2015 \mathrm{WS}$ and $834.6 \mathrm{~mm}$ in $2016 \mathrm{WS}$. The weekly rainfall pattern for 2015 WS and 2016 WS has been given in Figure 1A. To increase the chance that the drought experiment trials experienced droughtstress during the flowering stage, sowing time for drought trials was delayed about one month compared to the normal sowing time for this region. This practice was intended to postpone the flowering time to the end of the monsoon season. Nonstress condition trials were sown on June 23 and June 18, respectively, in 2015 WS and 2016 WS, whereas the sowing of drought experiment was on July 25, 2015 and July 20, 2016. Non-stress experiment was surface-flooded with irrigation to $1-5 \mathrm{~cm}$ depth throughout the crop growth till the ripening stage. Drought-stress experiment was maintained under the wellwatered condition from transplanting until 45 days when drained out of the paddy field, and irrigation was withheld to impose the drought stress. The stress was continued until severe leaf rolling (LR) and tip burning were observed in at least $75 \%$ of the population lines, and water table depth depleted up to 75 to $100 \mathrm{~cm}$ below the soil surface for more than two weeks. After that, life-saving irrigation was provided through flash flooding, and water was drained after $24 \mathrm{~h}$ to impose a second cycle of drought stress. This kind of drought imposition cycle was repeated till harvesting (Figure 1B).
Water table depth was measured by installing a 1.1-m unplasticized polyvinyl chloride carbonate (UPVC) pipe in experimental fields at regular intervals. Depletion in the water table was measured through a meter scale daily after the onset of the stress. This irrigation regime resulted in stress levels that caused LR and tip burning on most entries at the end of each drying cycle. The repeated stress cycles ensured that all entries experienced stress during the sensitive stage of 15 days before and after flowering. On average, this protocol has been found to reduce yield by $50 \%-70 \%$ relative to fully irrigated controls (Venuprasad et al., 2007).

\section{Data Collection and Statistical Analysis}

In all the trials, observation was recorded for days to $50 \%$ flowering (DTF), plant height (PHT), number of productive tillers (NPT), panicle length (PL), total number of grains per panicle (TGP), number of filled grains per panicle (TFGP), spikelet fertility percentage (SPF\%), plot yield (PY), biomass $(\mathrm{BM})$, and harvest index (HI). Data were recorded as per the standard evaluation system (IRRI SES, 2015).

The trait data in both stress and non-stress experiments were analyzed using restricted maximum likelihood (REML) methods for each season considering genotypes as a random effect and blocks as a fixed effect in the mixed-model procedure using GenStat for Windows 17th Edition, VSN International, Hemel Hempstead, United Kingdom ${ }^{1}$ (Patterson and Thompson, 1971). The variance components due to genotypes $\left(\sigma_{g}^{2}\right)$ for each trait and their respective standard errors were determined. Best linear unbiased predictors (BLUPs) were estimated for each line in each experiment along with standard errors to test the significance of variance components. Further phenotypic correlations were estimated to determine trait associations in GenStat 17.

\section{RESULTS}

\section{Phenotypic Evaluation of Parental Lines and Population}

Drought treatments in both years resulted in soil drying and subsequent yield reductions in parents and population compared with the well-watered control. The yield reduction in droughttolerant parent Chao Khaw under drought-stress environments (DSE), DSE-2015, and DSE-2016 was $61.72 \%$ and $54.12 \%$, respectively, whereas the reduction was much higher in droughtsensitive parent Kasturi in DSE-2015 (80.03\%) and DSE-2016 $(82.78 \%)$. The drought stress reduced $74.87 \%$ yield in the drought-tolerant cultivar Shabhagidhan in DSE-2015 and 70.35\% in DSE-2016. Overall, the imposed stress caused mean reductions in yield of over $60 \%$ (60.24\% in DSE-2015 and $64.86 \%$ in DSE-2016) in drought-stress trials than well-watered control. The population means for all the traits in the drought-stress environments were lower than the population means in the non-stress environment in both the years (Table 1).

The mean values for DTF of the population in DSE-2015 and DSE-2016 were 4-10 days less than NSE-2015 and NSE-2016.

\footnotetext{
${ }^{1}$ www.GenStat.co.uk
} 

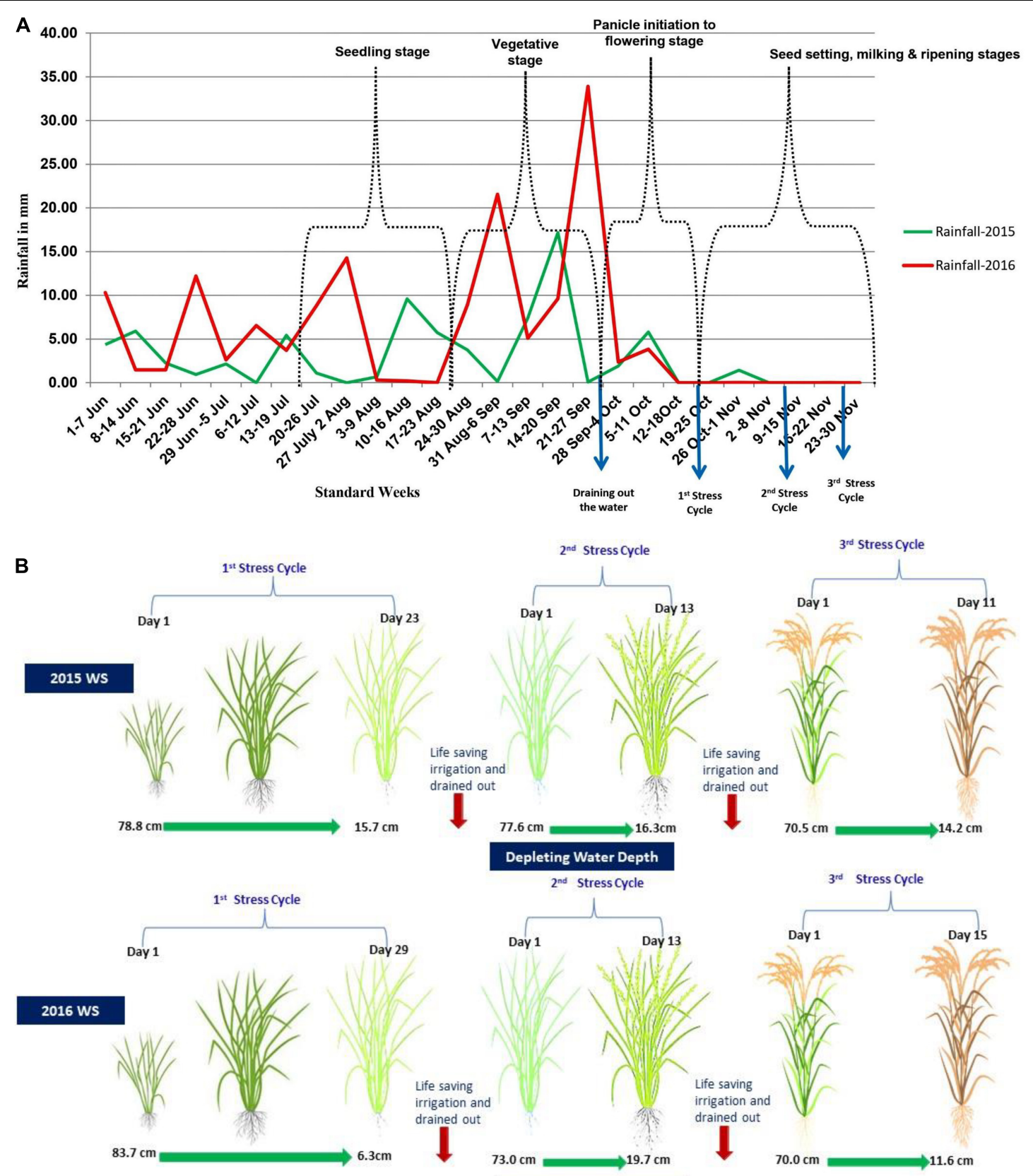

Depleting Water Depth

FIGURE 1 | (A) Weekly rainfall pattern in the wet seasons of 2015 and 2016 at IRRI, Hyderabad, India. (B) showing water table content of the stress-imposed field in both seasons of 2015 WS and 2016 WS.

As expected, the population mean for other traits, that is, PHT, NPT, PL, PY, BM, HI, TGP, TFGP, and SPF\% in both stress environments, was lower than the non-stress environments. It is worth mentioning that the reduction from non-stress to stress environment was higher in TFGP than TGP, which indicates the role of fertility breakdown in the breeding lines under stress conditions.

A single frame violin plot was drawn to visualize the phenotypic distribution of different traits across the environments for all the traits studied. The violin plots showed clear differentiation among stress and non-stress environments (Figure 2). The distribution shape of all the traits (skinny on each end and wide in the middle) indicates that the trait distribution is highly concentrated around the median.

Restricted maximum likelihood analysis for different components revealed that genotype variances were significant for all the traits studied based on the performance in individual drought-stress environments (2015 WS and 2016 WS) and 
TABLE 1 | Genetic parameter estimation of various traits under non-stress and drought-stress conditions for Kasturi $\times$ Chao Khaw derived population.

\begin{tabular}{|c|c|c|c|c|c|c|c|c|c|c|c|}
\hline Traits & Kasturi & Chao Khaw & Contrast analysis & Mean & SE & Min & Max & $\mathrm{H}^{2}(\%)$ & GCV (\%) & PCV (\%) & GAM (\%) \\
\hline \multicolumn{12}{|c|}{ Non-stress condition 2015} \\
\hline DTF (days) & 104 & 91 & $13^{\star \star}$ & 94 & 0.24 & 88 & 101 & 92.03 & 2.91 & 3.03 & 3.51 \\
\hline PHT (cm) & 99.92 & 102.90 & $2.98^{\star \star}$ & 88.45 & 0.57 & 75.60 & 108.19 & 92.95 & 7.75 & 7.78 & 6.03 \\
\hline NPT & 10 & 7 & $3.00^{\star *}$ & 7 & 0.10 & 5 & 9 & 81.02 & 15.06 & 16.73 & 100.94 \\
\hline $\mathrm{PL}(\mathrm{cm})$ & 25.70 & 22.06 & $3.64^{\star \star}$ & 21.45 & 0.11 & 19.52 & 23.57 & 68.23 & 4.49 & 5.44 & 15.26 \\
\hline $\mathrm{PY}(\mathrm{g})$ & 265.30 & 219.00 & $46.30^{\star \star}$ & 263.31 & 3.59 & 201.90 & 344.30 & 83.03 & 14.16 & 15.54 & 0.21 \\
\hline $\mathrm{BM}(\mathrm{g})$ & 511.00 & 472.40 & 38.60 & 587.89 & 11.82 & 370.00 & 1154.20 & 90.68 & 22.88 & 24.02 & 1.56 \\
\hline HI (\%) & 51.84 & 46.12 & $5.72^{\star \star}$ & 45.95 & 0.52 & 28.30 & 51.10 & 78.02 & 11.00 & 12.45 & 12.31 \\
\hline TGP & 176 & 157 & $19^{\star \star}$ & 155 & 1.93 & 104 & 220 & 90.48 & 14.02 & 14.74 & 4.61 \\
\hline TFGP & 160 & 142 & $18^{\star \star}$ & 138 & 1.81 & 103 & 186 & 82.07 & 13.48 & 14.88 & 4.73 \\
\hline SPF\% & 91.33 & 90.03 & 1.30 & 88.82 & 0.43 & 75.54 & 95.19 & 81.69 & 4.95 & 5.48 & 4.43 \\
\hline GY (Kg/ha) & 3316.00 & 2738.00 & $578.00^{\star \star}$ & 3291.40 & 44.90 & 2524.00 & 4304.00 & 83.03 & 14.16 & 15.54 & 0.21 \\
\hline \multicolumn{12}{|c|}{ Drought-stress condition 2015} \\
\hline DTF (days) & 97 & 86 & $11^{\star \star}$ & 90 & 0.25 & 86 & 94 & 73.81 & 2.56 & 2.98 & 2.9 \\
\hline $\mathrm{PHT}(\mathrm{cm})$ & 84.74 & 67.55 & $17.19^{\star \star}$ & 75.44 & 0.51 & 66.86 & 81.97 & 75.2 & 6.45 & 7.43 & 5.6 \\
\hline NPT & 6 & 6 & 0.00 & 6 & 0.06 & 5 & 7 & 79.95 & 10.36 & 11.59 & 96.88 \\
\hline $\mathrm{PL}(\mathrm{cm})$ & 21.06 & 18.3 & $2.76^{\star \star}$ & 20.34 & 0.1 & 18.95 & 23.16 & 73.14 & 4.31 & 5.04 & 16.63 \\
\hline $\mathrm{PY}(\mathrm{g})$ & 53 & 83.9 & $30.9^{\star \star}$ & 104.69 & 3.01 & 55.8 & 143 & 82.72 & 29.77 & 32.73 & 0.75 \\
\hline $\mathrm{BM}(\mathrm{g})$ & 184.9 & 179.7 & 5.2 & 270.09 & 7.91 & 120.3 & 497.2 & 85.16 & 31.16 & 33.76 & 3.77 \\
\hline HI (\%) & 27.53 & 47.07 & $19.54^{\star \star}$ & 39.94 & 0.85 & 28.37 & 52.58 & 80.91 & 21.41 & 23.8 & 20.36 \\
\hline TGP & 149 & 125 & $24^{\star \star}$ & 120 & 1.74 & 86 & 154 & 77.85 & 14.23 & 16.13 & 5.38 \\
\hline TFGP & 56 & 66 & $10^{\star \star}$ & 63 & 0.92 & 42 & 85 & 85.35 & 15.47 & 16.75 & 11.41 \\
\hline SPF\% & 37.66 & 53.13 & $15.47^{\star \star}$ & 52.83 & 0.34 & 48.73 & 57.1 & 84.93 & 6.77 & 7.34 & 8.97 \\
\hline GY (Kg/ha) & 662 & 1048 & $386^{\star \star}$ & 1308.61 & 37.7 & 698 & 1788 & 82.72 & 29.77 & 32.73 & 0.75 \\
\hline \multicolumn{12}{|c|}{ Non-stress condition -2016 } \\
\hline DTF (days) & 108 & 91 & $18^{\star \star}$ & 99 & 0.33 & 91 & 106 & 91.88 & 4.18 & 4.36 & 4.42 \\
\hline $\mathrm{PHT}(\mathrm{cm})$ & 100.3 & 103.2 & $2.9^{\star \star}$ & 109.89 & 0.66 & 89.5 & 126.9 & 92.62 & 8.95 & 9.3 & 6.77 \\
\hline NPT & 10 & 6 & $4^{\star \star}$ & 8 & 0.12 & 6 & 10 & 75.9 & 18.41 & 21.13 & 120.32 \\
\hline $\mathrm{PL}(\mathrm{cm})$ & 26.44 & 25.29 & $1.15^{\star \star}$ & 24.47 & 0.12 & 23.05 & 26.11 & 61.41 & 4.47 & 5.7 & 13.53 \\
\hline PY (g) & 287.6 & 239.3 & $48.3^{\star \star}$ & 362.62 & 4.25 & 206.6 & 495.7 & 83.55 & 13.86 & 15.16 & 0.17 \\
\hline $\mathrm{BM}(\mathrm{g})$ & 745.3 & 537 & $208.3^{\star \star}$ & 666.39 & 10.76 & 476.3 & 1172.8 & 81.25 & 36.9 & 40.94 & 3.61 \\
\hline HI (\%) & 39.84 & 45 & $5.16^{\star \star}$ & 55.05 & 0.85 & 34.17 & 64.43 & 82.49 & 20.96 & 23.08 & 19.57 \\
\hline TGP & 196 & 154 & $42^{\star \star}$ & 165 & 2.29 & 127 & 246 & 88.56 & 20.11 & 21.37 & 6.69 \\
\hline TFGP & 178 & 142 & $36^{\star \star}$ & 142 & 2.05 & 102 & 209 & 83.72 & 29.47 & 32.21 & 13.44 \\
\hline SPF\% & 90.42 & 90.16 & 0.26 & 86.14 & 0.54 & 70.06 & 96.45 & 62.25 & 7.62 & 9.66 & 6.88 \\
\hline GY (Kg/ha) & 3595 & 2991 & $604^{\star \star}$ & 4017.78 & 53.1 & 2154 & 4950 & 83.55 & 13.86 & 15.16 & 0.17 \\
\hline \multicolumn{12}{|c|}{ Drought-stress condition 2016} \\
\hline DTF (days) & 100 & 84 & $16^{\star \star}$ & 89 & 0.53 & 72 & 103 & 93.48 & 6.91 & 7.14 & 5.76 \\
\hline PHT (cm) & 86.32 & 67.2 & $19.12^{\star \star}$ & 86.28 & 0.66 & 71.48 & 105.99 & 91.6 & 8.79 & 9.19 & 6.63 \\
\hline NPT & 5 & 6 & $1^{\star \star}$ & 6 & 0.08 & 5 & 9 & 86.82 & 15.26 & 16.38 & 120.99 \\
\hline $\mathrm{PL}(\mathrm{cm})$ & 23.68 & 24.25 & 0.57 & 22.28 & 0.13 & 19.91 & 24.14 & 72.4 & 5.41 & 6.36 & 16.87 \\
\hline PY (g) & 49.5 & 109.8 & $60.3^{\star \star}$ & 112.94 & 2.34 & 69.2 & 191.8 & 90.6 & 23.5 & 24.68 & 0.66 \\
\hline $\mathrm{BM}(\mathrm{g})$ & 130.4 & 222.1 & $91.7^{\star \star}$ & 299.29 & 9.54 & 161.7 & 589.2 & 89.07 & 35.45 & 37.56 & 3.76 \\
\hline HI (\%) & 40.57 & 50.45 & $9.88^{\star \star}$ & 41.72 & 1.09 & 18.69 & 58.27 & 89.28 & 29.05 & 30.75 & 24.45 \\
\hline TGP & 132 & 157 & $25^{\star \star}$ & 126 & 1.35 & 105 & 168 & 85.15 & 11.38 & 12.33 & 4.9 \\
\hline TFGP & 60 & 93 & $33^{\star \star}$ & 73 & 0.89 & 54 & 93 & 85.36 & 13.02 & 14.1 & 9.07 \\
\hline SPF\% & 45.22 & 59.07 & $13.85^{\star \star}$ & 57.96 & 0.4 & 48.47 & 63.29 & 82.81 & 7.18 & 7.89 & 8.27 \\
\hline GY (Kg/ha) & 619 & 1372 & $753^{\star \star}$ & 1411.68 & 29.3 & 865 & 2397 & 90.6 & 23.5 & 24.69 & 0.66 \\
\hline
\end{tabular}

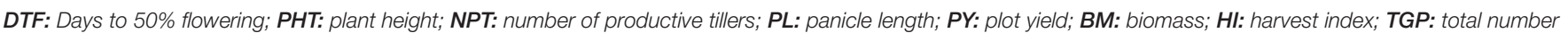
of grains per panicle; TFGP: total number of filled grains per panicle; SPF\%: spikelet fertility percentage; GY: yield in Kg/ha. ${ }^{* *}$ significant at $P \leq 0.01$. 

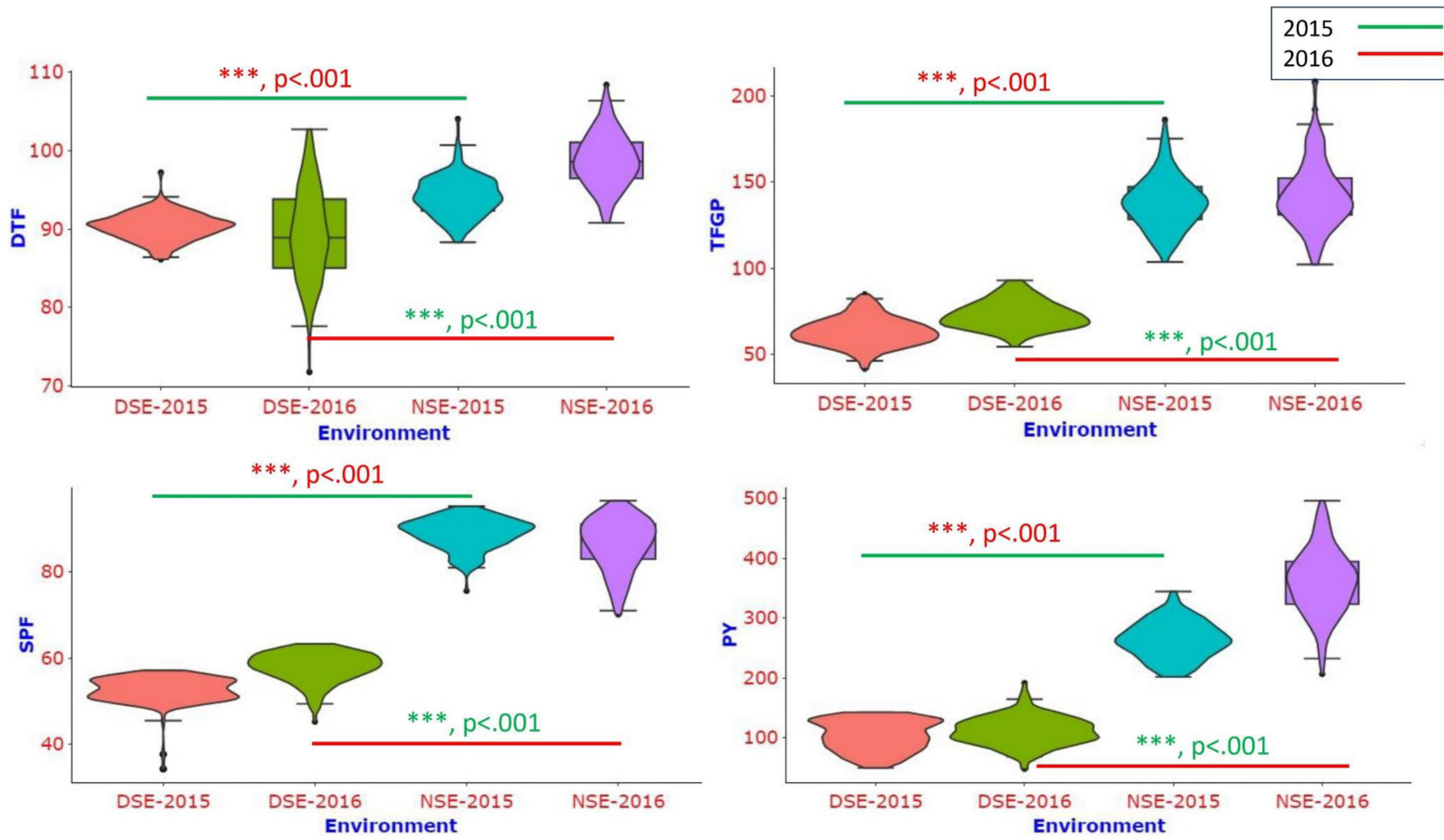

FIGURE 2 | The violin plot shows the phenotypic distribution of DTF, TFGP, SPF\% and PY traits in the population in different environments.

the non-stress environments (2015 WS and 2016 WS). PY's genotypic variance components $\left(\sigma^{2} \mathrm{~g}\right)$ were higher in NSE-2016 WS, followed by NSE-2015 WS than in DSE-2015 WS and DSE-2016 WS (Table 2). The $\sigma_{g}^{2}$ of SPF\% for both the non-stress environments were almost the same and higher than their respective stress environments. As expected, TGP and TFGP had much higher $\sigma_{g}^{2}$ in non-stress conditions than drought-stress conditions. The phenology trait, DTF, showed maximum $\sigma_{g}^{2}$ components in DSE-2016 WS followed NSE-2016 WS, NSE-2015 WS, and DSE-2015 WS. The highest GCV and PCV values were recorded in BM with $31 \%$ and $33 \%$ in DSE-2015 and $35 \%$ and $37 \%$ in DSE-2016. This was followed by PY (29\% \& 32\% and 23\% \& $24 \%)$ and $\mathrm{HI}(21 \%$ \& $23 \%$ and $29 \%$ \& 30\%) in DSE-2015 and DSE-2016, respectively.

All the traits' heritability estimates were very high in droughtstress environments and non-stress environments with a range of $73.14 \%$ to $85.35 \%$ in DSE-2015 and $72.4 \%$ to $93.48 \%$ in DSE-2016. All the traits in the non-stress trials, too, showed high heritability. The heritability of a few traits was greater in non-stress, and for some, it was greater in stress environments, which is consistent across the years. In general, there were more negligible differences in heritability between the stress environments of 2015 and 2016. Also, it should be noted that no significant differences in heritability were observed between stress and non-stress environments. In both the drought-stress conditions, only two traits, NPT (96.88\% and $120.99 \%$ in DSE 2015 and DSE 2016, respectively) and HI (20.36\% and 24.45\% in DSE 2015 and DSE 2016, respectively), showed a very high genetic advance of mean (GAM).

The Pearson's correlation analysis for different yield contributing traits under stress and non-stress conditions revealed that only $\mathrm{BM}$ and $\mathrm{HI}(0.22-0.65)$ were associated with grain yield in stress and non-stress environments (Supplementary Table 1). Days to flowering, plant height, number of panicles per tiller, panicle length, total number of grains per panicle, and total number of filled grains per panicle showed no correlation with grain yield in the non-stress environment and stress environments (Figures 3, 4).

\section{Identification of Promising Breeding Lines for Rainfed Lowland Ecology}

In this experimental screening, we have found some transgressive segregants, which yielded much better than the popular mega variety, IR 64. These breeding lines may or may not have the drought-tolerant capacity but showed their yield superiority under well-watered conditions. A total of 34 breeding lines were found to have a significantly higher yield than the mega variety, IR 64. More than half of the breeding lines (21 lines) yielded more than $4,000 \mathrm{~kg} / \mathrm{ha}$. These breeding lines flowered earlier than the female parent Kasturi with 92 to 100 days falling in the medium maturity group and at par with IR 64 (Supplementary Table 2).

\section{Identification of Promising Breeding Lines for Rainfed Upland Ecology}

Some drought-tolerant breeding lines for the areas in rainfed upland and highly drought-prone ecologies were identified from this study irrespective of their performance in the well-watered condition. We found 48 breeding lines with an average yield of $1,650 \mathrm{~kg} / \mathrm{ha}$ and spans from 1,446 to $1,934 \mathrm{~kg} / \mathrm{ha}$. In contrast, the drought-tolerant popular variety Shabhagidhan and donor parent Chao Khaw yielded an average of $940 \mathrm{~kg} / \mathrm{ha}$ and $1,210 \mathrm{~kg} / \mathrm{ha}$, 


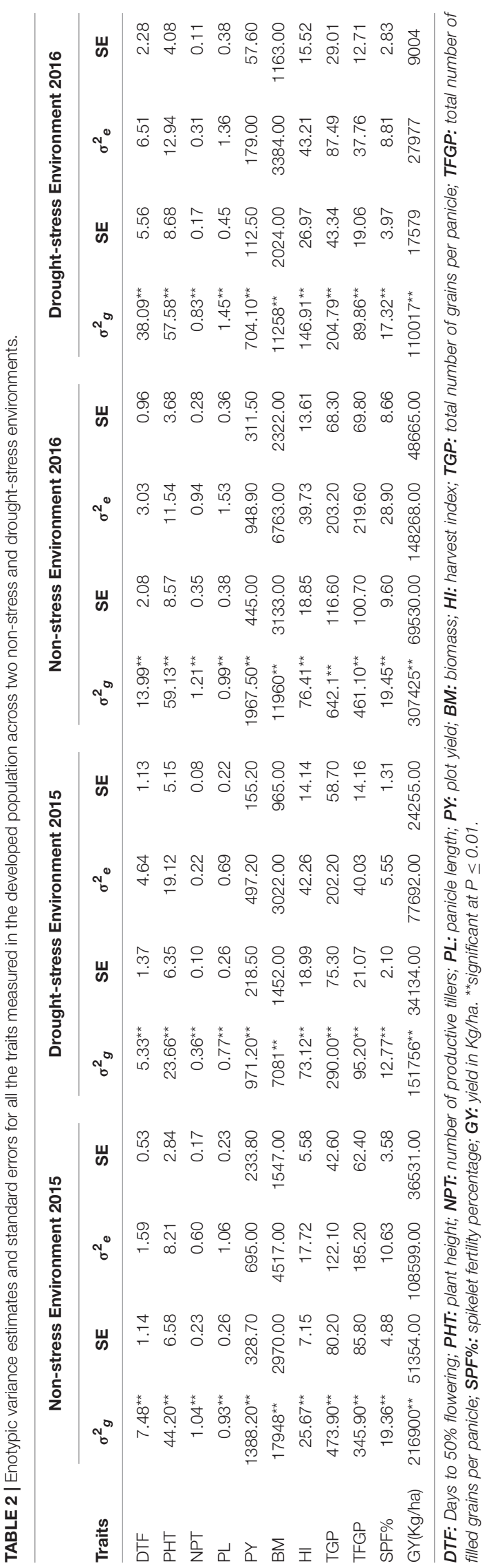

respectively, over two years. The female parent Kasturi yielded just above half-ton per hectare. All the breeding lines under the drought stress condition were in the medium maturity group (86-96 days) with semidwarf plant type $(73-91 \mathrm{~cm})$. In contrast, the female parent Kasturi flowered in 104 days and the tolerant donor flowered in 91 days. The spikelet fertility of those breeding lines was $49 \%-58 \%$ under severe drought conditions (Supplementary Table 3).

\section{Promising Breeding Lines Suited for Rainfed Lowland Ecology With Occasional Drought Occurrence}

This study identified 21 breeding lines common across the nonstress, and stress environments of 2015 WS and 2016 WS showed better yield performance than the tolerant check Shabhagidhan and tolerant donor Chao Khaw. These 21 breeding lines were selected from the 48 drought-tolerant promising breeding lines and 34 promising breeding lines in non-stress conditions. The top 14 breeding lines yielded more than $4,000 \mathrm{~kg} / \mathrm{ha}$ $(4,060 \mathrm{~kg} / \mathrm{ha}$ to $4,363 \mathrm{~kg} / \mathrm{ha})$, and the average yield of the same 14 breeding lines, under drought stress, was $1,537 \mathrm{~kg} / \mathrm{ha}(1,165$ to $1,903 \mathrm{~kg} / \mathrm{ha}$ ) (Table 3).

Overall, all the 21 breeding lines yielded more than $3,500 \mathrm{~kg} / \mathrm{ha}$ $(3,775 \mathrm{~kg} / \mathrm{ha}$ to $4,363 \mathrm{~kg} / \mathrm{ha})$ in non-stress conditions and more than $1,000 \mathrm{~kg} / \mathrm{ha}(1,165 \mathrm{~kg} / \mathrm{ha}$ to $1,903 \mathrm{~kg} / \mathrm{ha})$. In contrast, drought-tolerant Shabhagidhan had 3,407 kg/ha and $940 \mathrm{~kg} / \mathrm{ha}$ in non-stress and drought stress conditions, respectively, whereas the donor parent Chao Khaw yielded $1,210 \mathrm{~kg} / \mathrm{ha}$ in stress $2,864 \mathrm{~kg} / \mathrm{ha}$ in a non-stress environment. Though Kasturi is a high-yielding variety, the yield was $640 \mathrm{~kg} / \mathrm{ha}$, which indicates its drought sensitivity under stress conditions. Interestingly, all the identified breeding lines flowered between 92 and 100 days in well-watered conditions and 83-96 days under stress conditions indicating they fall into medium-maturity groups. We also found that all the 21 breeding lines are semidwarf plant types (92-109 $\mathrm{cm}$ in non-stress and $75-86 \mathrm{~cm}$ in stress days). These breeding lines also have high tillering capacity with 6-8 productive tillers per hill.

\section{DISCUSSION}

Erratic rainfall distribution in rainfed areas and depleting the ground water level in irrigated areas threaten rice production globally and demand the urgent need to develop rice cultivars capable of producing more from diminishing water resources. The drought-tolerant rice varieties are believed to reduce rice production risk in rainfed areas, increase productivity in the changing climatic scenario, and alleviate poverty in rice-growing areas. Breeders need to adopt adapted solutions and strategies to respond to a different kind of drought situations based on the precise characteristics of different rice ecologies. For instance, the rice ecology of Eastern India receives sufficient rainfall, and so, rice is grown in rainfed conditions. However, due to erratic rain once in a few years, occasional drought leads to drastic yield reduction. Hence, rice drought breeding includes diverse approaches suitable for various rice ecologies and needs. For 


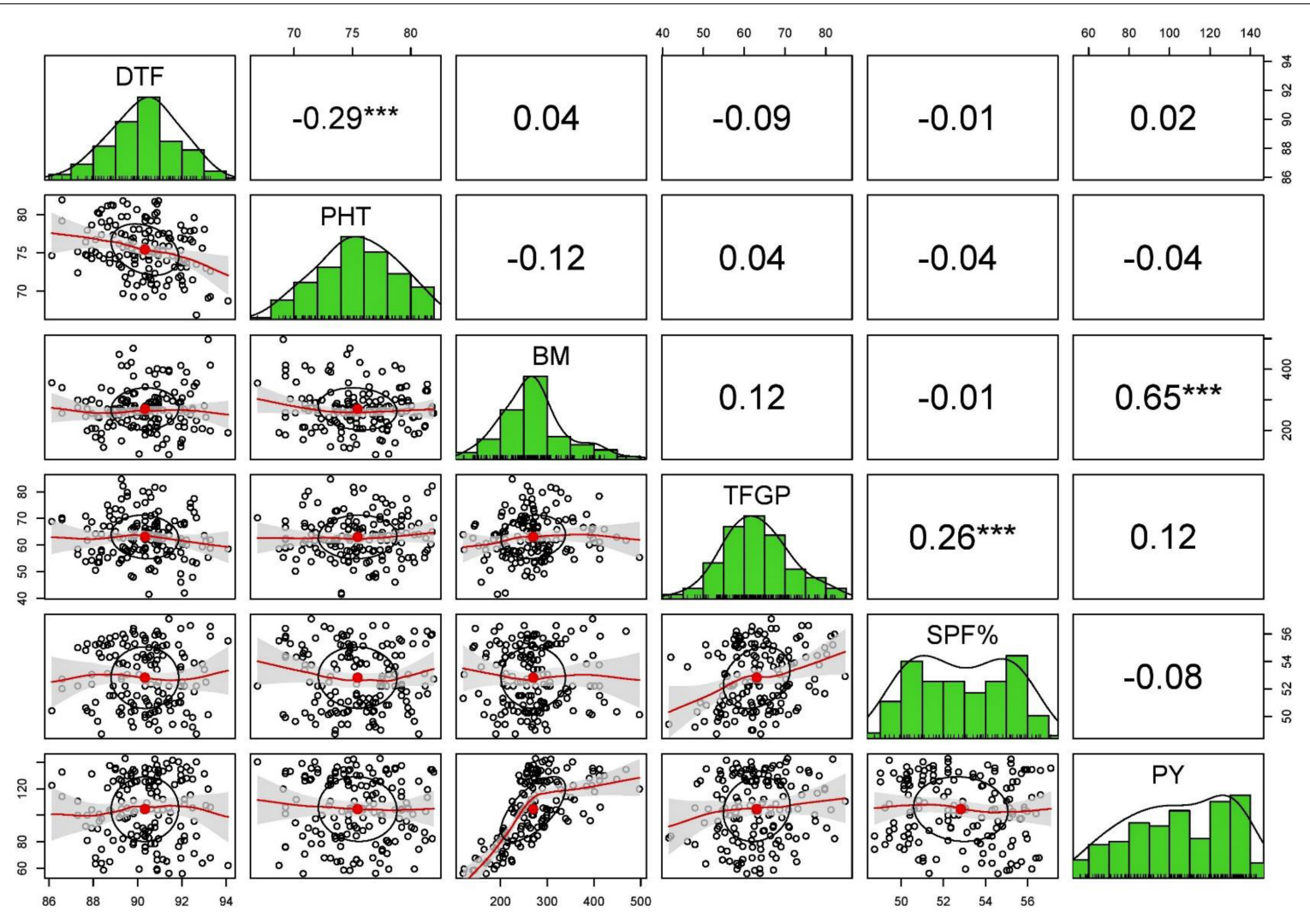

FIGURE 3 | The scatterplot matrix shown here has histograms of the variables in the diagonal, and correlation coefficients in the upper part of the matrix under stress condition of 2015 WS.

decades, traditional farmers have grown many landraces that may have low-yielding capacity but can mitigate the abiotic stress. Modern breeding strategies of elite $\mathrm{x}$ elite crosses for developing the high yielding ignore the need for landraces in the breeding programs. The underutilized landraces and their hidden treasures of tolerant genes/ QTLs may help impart the maximum wateruse efficiency in the elite modern breeding lines under alleviating the drought stress.

Though many studies have been conducted over the last two decades to develop drought-tolerant lines in rice, limited reports are in the public domain, where drought breeding programs involve exotic drought-tolerant landrace and popular aromatic cultivars. One such exotic landrace is Chao Khaw from Laos, which is considered an excellent drought-tolerant line with hidden drought-stress tolerant QTLs or genes. On the other hand, Kasturi, an aromatic rice variety, has high-yielding potential, excellent milling quality, blast resistance, and stem borer tolerance but is sensitive to water stress.

Drought screening, differentiating high-yielding and droughtsensitive lines from drought-tolerant ones and their yield gaps under non-stress and stress conditions, is considered adequate for selecting drought-tolerant higher-yielding lines. In this study, the drought stress experiments with imposed three cycles of stress and adjustment of sowing to avoid heavy rainfall, could accurately distinguish the drought-tolerant and drought-sensitive lines. The literature cites that if a lowland drought screening experiment reduces yield in the range of $30 \%, 31 \%-65 \%$, and $65 \%-85 \%$, then the drought should be considered mild, moderate, and severe types, respectively, and appropriate for drought tolerance breeding (Kumar et al., 2007). Yield reduction under drought stress is a common phenomenon reported in many studies earlier (Kamoshita et al., 2008; Ndjiondjop et al., 2010; Sandhu and Kumar, 2017; Bhattarai and Subudhi, 2018). The reduction of almost $80 \%$ yield in the sensitive parent Kasturi confirms the severity of drought of the two stress trials.

Along with the grain yield, other traits such as plant height, harvest index, spikelet fertility percentage, and the total number of filled grains showed reduced values under drought stress compared to the non-stress conditions. The reduction of spikelet fertility percentage under drought stress is considered crucial for yield reduction in rice under stress (Seyoum et al., 2012; Hasanuzzaman et al., 2014; Swamy et al., 2017). In this study, a reduction of about $30 \%-40 \%$ in spikelet fertility has been observed, subsequently, the yield reduction.

The mixed model REML analysis of variance revealed a significant variation among the breeding lines for all the traits across the environments. Furthermore, this confirms the fact that a good amount of segregation exists for the studied traits. Parents differed significantly for all the traits in both the droughtstress environments, which was also observed by previous 

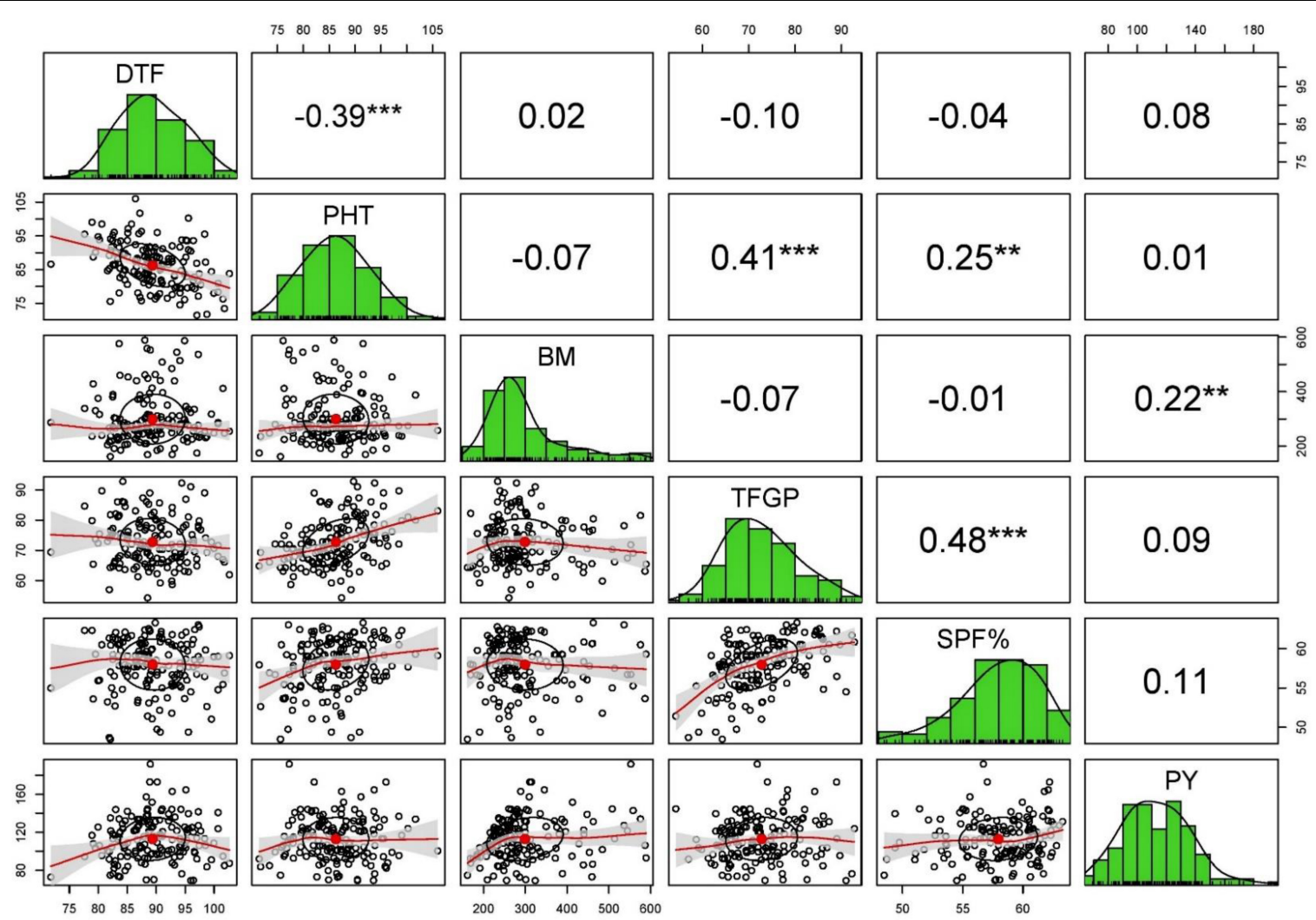

FIGURE 4 | The scatterplot matrix shown here has histograms of the variables in the diagonal, and correlation coefficients in the upper part of the matrix under stress condition of 2016 WS.

studies (Venuprasad et al., 2007; Kumar et al., 2008). Parents' significant difference in drought tolerance attributes, especially under drought-stress environments, validated the experimental conditions for evaluating drought tolerance breeding lines. The water depth level from the three stress cycles also confirmed the trials' perfect drought-stress condition.

From the ranges of various traits across the environments and years, it is evident that most of the traits were higher in NSE-2016. The comparably high rainfall during 2016 non-stress conditions may be the reason for that. Under the drought stress conditions, except TFGP, the range of all traits was higher in DSE-2016 than in DSE-2015. The high groundwater level of the trial fields in all the three stress cycles in DSE-2016 was high compared to DSE-2015 which further confirms the large variability in DSE-2016 than DSE-2015. In short, the comparable favorable conditions of DSE-2016 were helpful in the expression of the breeding lines variably. It seems that the range of PHT and NPT was least affected across the trials except for DSE-2015. The relatively higher range of $\mathrm{HI}$ in drought-stress conditions indicates that there must be few breeding lines with a superior capacity of both sink and source and convert the photosynthates into usable economic yield.

All the breeding lines are grouped into the early to midearly groups. Both the parents were from the early to medium category, and none of the parents was in the late category, which may be the reason for low variability in the population for flowering. Similarly, the low difference between parents for
$\mathrm{PH}$ and PL may be responsible for the low variability of those traits. As expected, for PY, comparatively low variability was observed under non-stress conditions than the drought-stress conditions. High variability under the stress condition implicates stress-induced additional variability among the breeding lines through upregulation or downregulation of genes responsible for drought mitigation in plants. Like PY, HI also showed higher stress conditions than non-stress conditions reflecting the stress-induced variability in the population under droughtstress conditions.

The heritability estimates were found more or less similar in stress and non-stress environments and high for all the traits studied. No consistent reductions in heritability under severe drought stress were visible; in some cases, the heritability was higher in the stress environment. Heritability values of $>70 \%$ for phenological traits and grain yield were also reported earlier (Vikram et al., 2011; Dixit et al., 2014a,b; Swamy et al., 2017; Solis et al., 2018). The relatively similar heritability estimates for grain yield under stress and non-stress situations indicate that selection for grain yield under water stress in rice is possible with the same level of precision as that achieved in non-stress (Kumar et al., 2008). This result confirms other reports that the heritability of grain yield under reproductive stage stress is comparable to that in non-stress trials (Lafitte and Courtois, 2000; Atlin and Lafitte, 2002; Babu et al., 2003; Atlin et al., 2004; Lanceras et al., 2004; Venuprasad et al., 2007; Kumar et al., 2008). This study also validates the hypothesis 


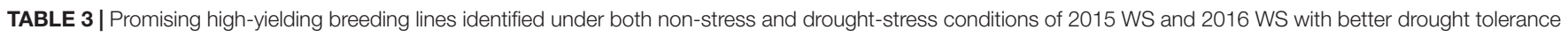
over the popular drought-tolerant check Shabhagidhan and drought-tolerant donor parent Chao Khaw.

\begin{tabular}{|c|c|c|c|c|c|c|c|c|c|c|c|c|c|c|c|c|c|c|c|}
\hline \multirow[b]{2}{*}{ SI. No. } & \multirow[b]{2}{*}{$\begin{array}{l}\text { Promising Breeding } \\
\text { lines }\end{array}$} & \multicolumn{2}{|c|}{ DTF } & \multicolumn{2}{|c|}{ PHT } & \multicolumn{2}{|c|}{ PY } & \multicolumn{2}{|c|}{ BM } & \multicolumn{2}{|r|}{ HI } & \multicolumn{2}{|c|}{ TGP } & \multicolumn{2}{|c|}{ TFGP } & \multicolumn{2}{|c|}{ SPF $\%$} & \multicolumn{2}{|c|}{ GY (Kg/ha) } \\
\hline & & NS & DS & NS & DS & NS & DS & NS & DS & NS & DS & NS & DS & NS & DS & NS & DS & NS & DS \\
\hline 1 & IR 128807-82-B & 98 & 90 & 96.65 & 75.46 & 352.65 & 120.75 & 673.9 & 243.45 & 53.1 & 49.78 & 161 & 129 & 140 & 69 & 87.17 & 53.95 & 4364 & 1510 \\
\hline 2 & IR 128807-96-B & 95 & 87 & 95.19 & 84.05 & 345.1 & 117.85 & 675.9 & 333.4 & 51.84 & 37.87 & 175 & 118 & 22 & 65 & 88.71 & 55.77 & 4289 & 1474 \\
\hline 3 & IR 128807-11-B & 100 & 96 & 109.31 & 76.02 & 385.35 & 138.7 & 732.7 & 273.2 & 52.62 & 51.02 & 167 & 124 & 148 & 65 & 90.1 & 52.51 & 4269 & 1733 \\
\hline 4 & IR 128807-175-B & 98 & 87 & 93.21 & 80.98 & 335.7 & 139.45 & 623.45 & 284.35 & 53.47 & 48.31 & 149 & 122 & 130 & 70 & 86.69 & 56.8 & 4217 & 1743 \\
\hline 5 & IR 128807-17-B & 95 & 90 & 101.94 & 82.62 & 332.4 & 152.25 & 594.9 & 284.25 & 54.57 & 52.88 & 142 & 119 & 126 & 67 & 87.71 & 56.37 & 4200 & 1903 \\
\hline 6 & IR 128807-22-B & 96 & 83 & 100.24 & 83.98 & 328.95 & 111.1 & 692.5 & 384.1 & 48.31 & 31.45 & 150 & 127 & 138 & 68 & 91.85 & 52.81 & 4143 & 1389 \\
\hline 7 & IR 128807-127-B & 92 & 88 & 96.08 & 78.81 & 329.25 & 93.25 & 662.4 & 262.15 & 50.51 & 36.94 & 184 & 130 & 151 & 77 & 83.43 & 58.24 & 4143 & 1166 \\
\hline 8 & IR 128807-100-B & 97 & 92 & 102.58 & 76.83 & 326.9 & 103.35 & 597.1 & 427.15 & 54.1 & 30.23 & 160 & 130 & 142 & 70 & 89.71 & 53.18 & 4136 & 1292 \\
\hline 9 & IR 128807-5-B & 99 & 96 & 101.01 & 79.25 & 373.25 & 117.95 & 661.85 & 274.05 & 55.72 & 43.63 & 181 & 120 & 151 & 68 & 84.29 & 57.07 & 4113 & 1475 \\
\hline 10 & IR 128807-99-B & 97 & 88 & 94.91 & 85.7 & 326.85 & 127.95 & 675.45 & 255.3 & 49.58 & 52.03 & 160 & 125 & 147 & 71 & 92.7 & 56.53 & 4111 & 1600 \\
\hline 11 & IR 128807-3-B & 99 & 94 & 94.51 & 76 & 330.45 & 115.7 & 1124.6 & 364.1 & 35.64 & 39.55 & 158 & 119 & 142 & 63 & 89.72 & 53.06 & 4102 & 1446 \\
\hline 12 & IR 128807-12-B & 97 & 90 & 101.95 & 79.55 & 324 & 149.5 & 637.5 & 304.05 & 50.85 & 49.15 & 175 & 121 & 138 & 69 & 79.04 & 56.61 & 4082 & 1869 \\
\hline 13 & IR 128807-46-B & 96 & 94 & 102.7 & 85.18 & 327.75 & 115.65 & 579.75 & 249.75 & 55.38 & 47.42 & 181 & 122 & 160 & 67 & 89.77 & 54.99 & 4068 & 1446 \\
\hline 14 & IR 128807-155-B & 96 & 90 & 102.72 & 80.09 & 321.4 & 118.4 & 582.75 & 284.5 & 54.25 & 41.95 & 139 & 103 & 121 & 57 & 85.24 & 55.81 & 4061 & 1480 \\
\hline 15 & IR 128807-147-B & 96 & 94 & 92.29 & 79.82 & 317.6 & 97.2 & 648.15 & 219 & 49.41 & 45.25 & 160 & 126 & 143 & 72 & 88.25 & 57.05 & 3992 & 1216 \\
\hline 16 & IR 128807-73-B & 99 & 94 & 98.79 & 83.04 & 316.6 & 119.7 & 630.5 & 245.85 & 50.37 & 49.62 & 202 & 118 & 166 & 66 & 85.23 & 56.13 & 3968 & 1496 \\
\hline 17 & IR 128807-16-B & 97 & 89 & 102.31 & 85.2 & 327.65 & 128.75 & 665.35 & 265.95 & 51.05 & 49.66 & 146 & 131 & 126 & 74 & 85.1 & 56.53 & 3962 & 1610 \\
\hline 18 & IR 128807-38-B & 95 & 91 & 99.97 & 83.31 & 324.55 & 123 & 595.95 & 259.25 & 54.5 & 49.09 & 164 & 132 & 139 & 73 & 84.38 & 55.37 & 3950 & 1538 \\
\hline 19 & IR 128807-163-B & 96 & 90 & 99.51 & 81.24 & 348.85 & 136.85 & 621.7 & 430.05 & 54.34 & 34.07 & 141 & 122 & 117 & 66 & 80.75 & 54.13 & 3892 & 1711 \\
\hline 20 & IR 128807-39-B & 95 & 89 & 96.93 & 78.75 & 316.95 & 135.9 & 601.45 & 277.65 & 53.17 & 49.25 & 163 & 137 & 138 & 80 & 84.6 & 57.75 & 3866 & 1699 \\
\hline \multirow[t]{8}{*}{21} & IR 128807-95-B & 95 & 90 & 101.95 & 80.14 & 309.8 & 139.3 & 628.6 & 286.4 & 50.1 & 48.7 & 159 & 122 & 144 & 71 & 91.27 & 58.31 & 3775 & 1742 \\
\hline & Mean & 97 & 91 & 99.27 & 80.76 & 333.43 & 123.93 & 662.21 & 295.62 & 51.56 & 44.66 & 163 & 124 & 141 & 69 & 86.94 & 55.66 & 4081 & 1549 \\
\hline & Min & 92 & 83 & 92.29 & 75.46 & 309.8 & 93.25 & 579.75 & 219 & 35.64 & 30.23 & 139 & 103 & 117 & 57 & 79.04 & 52.51 & 3775 & 1166 \\
\hline & Max & 100 & 96 & 109.31 & 85.7 & 385.35 & 152.25 & 1124.6 & 430.05 & 55.72 & 52.88 & 202 & 137 & 166 & 80 & 92.7 & 58.31 & 4364 & 1903 \\
\hline & $\begin{array}{l}\text { Chao Khaw (Donor } \\
\text { parent) }\end{array}$ & 91 & 85 & 103.05 & 67.375 & 229.15 & 96.85 & 504.70 & 200.9 & 45.56 & 48.76 & 156 & 141 & 141 & 79 & 90.10 & 56.1 & 2865 & 1210 \\
\hline & IR 64 (Check) & 92 & 89 & 79.04 & 68.485 & 288.25 & 49.3 & 594.10 & 145.35 & 49.34 & 34.575 & 172 & 138 & 157 & 61 & 91.27 & 46.475 & 3603 & 617 \\
\hline & $\begin{array}{l}\text { Kasturi (Recipient } \\
\text { parent) }\end{array}$ & 106 & 98 & 100.11 & 85.53 & 276.45 & 51.25 & 628.15 & 157.65 & 45.84 & 34.05 & 186 & 141 & 169 & 58 & 90.88 & 41.44 & 3456 & 641 \\
\hline & $\begin{array}{l}\text { Shabhagidhan } \\
\text { (Drought-tolerant } \\
\text { check) }\end{array}$ & 95 & 90 & 101.68 & 65.46 & 272.55 & 75.2 & 571.35 & 194.45 & 48.90 & 38.965 & 179 & 138 & 164 & 71 & 91.56 & 51.47 & 3407 & 940 \\
\hline
\end{tabular}

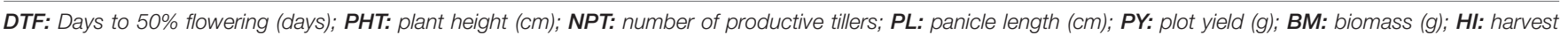
index (\%); TGP: total number of grains per panicle; TFGP: total number of filled grains per panicle; SPF\%: spikelet fertility percentage; GY: yield in Kg/h.

that yield evaluation under reproductive drought stress in rice can be conducted with a precision roughly equivalent to that obtained for non-stress trials and indicate that direct selection for grain yield under drought stress will result in gains if screening trials are well managed (Atlin and Lafitte, 2002).

The significant positive association observed between grain yield and harvest index under stress indicates that the yield differences we observed under drought stress were primarily due to the vast variation in plants' capacity to maintain seed set under stress, apart from accumulating biomass. This result is consistent with previous studies, which reported that the reduction in yield when the drought stress is applied during flowering time is mainly due to spikelet sterility (Liu et al., 2006). As there was no correlation between days to flowering and grain yield in both non-stress and drought-stress conditions, it is evident that the drought tolerance shown by some breeding lines is due to the drought tolerance per se of those breeding lines than drought escape. There was no advantage of tall, semidwarf, or dwarf plants in influencing the yield under both non-stress and stress conditions as no association of plant height and grain yield was observed in both the conditions.

Similarly, in high yield, NPT and PL had no role, which indicate that breeding lines with more productive tillers and panicle length could have a more significant number of chaffy seeds or the weight of the seed was lower compared to other breeding lines with less productive tillers or panicle length but with high seed weight. As expected, in this studied population, TGP had no association with grain yield under both the conditions across the season, pointing out that the breeding lines behaved differently in producing filled grains. Many breeding lines might have many grains but many chaffy grains, whereas breeding lines may have few grains but more filled grains. This phenomenon is also reflected by spikelet fertility percentage as SPF\% also showed no correlation with grain yield. 
There is no correlation between SPF\% and grain yield which indicates that many low-yielding breeding lines are present in the population with high spikelet fertility. In other words, due to the smaller number of grains per panicle, these breeding lines could translocate the photosynthates to the majority of the grains. Except for biomass and harvest index, the absence of correlation with other traits with grain yield inferred that the breeding lines showed a very linear relationship with biomass and harvest index, but different breeding lines behaved differently with other traits. Hence, more biomass accumulation and plants' capacity to maintain the good source-sink relationship under both conditions are beneficial to get a higher yield. No correlation between the number of filled grains and grain yield indicates the seed weight and the seed length, which may play an essential role in determining the grain yield rather than filled grains. The secondary traits included in this study were ineffective toward grain yield under stress and confirmed the earlier studies (Atlin and Lafitte, 2002; Kumar et al., 2008).

Two breeding lines yielded almost two times more than the tolerant check, Shabhagidhan, and 1.5 times the tolerant parent, Chao Khaw. This confirms that it is possible to select superior stress-tolerant breeding lines directly selecting grain yield under stress conditions from tolerant or sensitive crosses. These results have similarities with (Kumar et al., 2008), where they found breeding lines superior by $2-2.5$ times than the tolerant parent. In the rainfed areas, farmers grow many traditional drought-tolerant but low-yielding cultivars that perform poorly if an occasional drought happens. The drought occurrence in Eastern India was almost two times in five years, whereas once in five years in northeast Thailand, an important rice ecology (Bhandari et al., 2007; Prapertchob et al., 2007). Hence, farmers need drought-tolerant varieties with high-yielding potential under favorable years but acceptable yield under moderate or severe drought conditions (Kumar et al., 2008). In our selection of drought-tolerant breeding lines in the populations, we observed transgressive segregants that yielded significantly higher than the parents under drought and well-watered conditions. These breeding lines were also found significantly better than the widespread drought-tolerant check Shabhagidhan. The promising breeding lines identified showed consistent performance across the years and hence are stable. Out of 21 breeding lines, 14 breeding lines yielded more than $4,000 \mathrm{~kg} / \mathrm{ha}$ under the non-stress condition and yielded more than $1,474 \mathrm{~kg} / \mathrm{ha}$ under severe drought stress. Under the same level of stress, the popular mega variety IR64 yielded only $616 \mathrm{~kg} / \mathrm{ha}$.

\section{CONCLUSION}

In conclusion, this study revealed the availability of large genetic variation with high heritability in the studied population

\section{REFERENCES}

Atlin, G. (2003). Improving drought tolerance by selecting for yield. Breeding Rice for Drought-prone Environments. Int. Rice Res. Inst 2003:14. under both the drought-stress and non-stress conditions. The sufficient variation under drought stress confirms that the population was perfect for studying rice drought tolerance behavior. The imposed drought condition, which made the water depth level below the recommended level, provides the ideal condition for drought tolerance study. The studied population needs to be evaluated in multiseason and locations to know the significant genotype-environment interactions. The promising breeding lines identified suitable for different ecologies should extensively be evaluated under multilocation trials (MLTs) for immediate release as varieties or use as a donor in breeding programs.

\section{DATA AVAILABILITY STATEMENT}

The original contributions presented in the study are included in the article/Supplementary Material, further inquiries can be directed to the corresponding authors.

\section{AUTHOR CONTRIBUTIONS}

$\mathrm{AK}, \mathrm{PK}, \mathrm{CV}$, and VS involved in conceptualization and methodology. CV contributed in field trial establishment and data collecting. CV, PP, and AS involved in statistical analysis. $\mathrm{PP}$ and VS contributed in writing original draft preparations. $\mathrm{VS}, \mathrm{AK}$, and PK involved in writing, reviewing, and editing. All authors have read and agreed to the published version of the manuscript.

\section{ACKNOWLEDGMENTS}

We would like to acknowledge K. Anil and Satya Babu for their help in the experimental field establishment. We express sincere thanks to the Department of Biotechnology (DBT), Government of India, for financial support under the project "Development of superior haplotype-based nearisogenic lines (Haplo-NILs) for enhanced genetic gain in rice" (grant BT/PR32853/AGill/103/1159/2019). This work has been undertaken under the ICAR-IRRI collaborative research project. IRRI is a member of the CGIAR Consortium.

\section{SUPPLEMENTARY MATERIAL}

The Supplementary Material for this article can be found online at: https://www.frontiersin.org/articles/10.3389/fpls.2022. 814774/full\#supplementary-material

Atlin, G. N., and Lafitte, H. R. (2002). "Marker-Assisted Breeding versus Direct Selection for Drought Tolerance in Rice," in Field Screening for Drought Tolerance in Crop Plants with Emphasis on Rice: Proceedings of an International Workshop on Field Screening for Drought Tolerance in Rice, 
ICRISAT, Patancheru, India, 11-14 Dec 2000, (New York, NY: The Rockefeller Foundation), 71.

Atlin, G. N., Lafitte, R., Venuprasad, R., Kumar, R., and Jongdee, B. (2004). Heritability of rice yield under reproductive-stage drought stress, correlations across stress levels, and effects of selection: implications for drought tolerance breeding. Resilient Crops Water Limit. Env. 2004:85.

Babu, R. C., Nguyen, B. D., Chamarerk, V., Shanmugasundaram, P., Chezhian, P., Jeyaprakash, P., et al. (2003). Genetic Analysis of Drought Resistance in Rice by Molecular Markers: Association between Secondary Traits and Field Performance. Crop Sci. 43, 1457-1469. doi: 10.2135/cropsci2003.1457

Bates, B. C., Kundzewiez, Z. W., Wu, S., and Palutikof, J. P. (eds) (2008). Climate Change and Water. Technical Paper of the Intergovernmental Panel on Climate Change. Geneva: IPCC Secretariat, 210.

Bhandari, H., Pandey, S., Sharan, R., Naik, D., Hirway, I., Taunk, S. K., et al. (2007). Economic costs of drought and rice farmers' drought-coping mechanisms in eastern India. Economic costs of drought and rice farmers' coping mechanisms: a cross-country comparative analysis. Los Banos: International Rice Research Institute (IRRI), 43-111.

Bhattarai, U., and Subudhi, P. K. (2018). Identification of drought responsive QTLs during vegetative growth stage of rice using a saturated GBS-based SNP linkage map. Euphytica 214:38. doi: 10.1007/s10681-018-2117-3

Dixit, S., Singh, A., and Kumar, A. (2014a). Rice Breeding for High Grain Yield under Drought: a Strategic Solution to a Complex Problem. International Journal of Agronomy 2014, 1-15. doi: 10.1155/2014/863683

Dixit, S., Huang, B. E., Sta, Cruz, Ma, T., Maturan, P. T., Ontoy, J. C. E., et al. (2014b). QTLs for Tolerance of Drought and Breeding for Tolerance of Abiotic and Biotic Stress: an Integrated Approach. PLoS One 9:e109574. doi: 10.1371/ journal.pone.0109574

Hasanuzzaman, M., Nahar, K., Gill, S. S., and Fujita, M. (2014). Drought Stress Responses in Plants, Oxidative Stress, and Antioxidant Defense. Climate change and plant abiotic stress tolerance. Weinheim: Wiley Blackwell, 209-250.

Henry, A., Gowda, V. R. P., Torres, R. O., McNally, K. L., and Serraj, R. (2011). Variation in root system architecture and drought response in rice (Oryza sativa): phenotyping of the OryzaSNP panel in rainfed lowland fields. Field Crops Res. 120, 205-214. doi: 10.1016/j.fcr.2010.10.003

Huke, R. E., and Huke, E. H. (1997). Rice Area by Type of Culture: South, Southeast, and East Asia. Los Baños: IRRI.

IRRI SES (2015). Standard Evaluation System for Rice (SES). IRRI SES2015. Available online at: http://www.knowledgebank.irri.org/images/docs/ rice-standard-evaluation-system.pdf (Accessed on 11 Oct, 2021)

Kamoshita, A., Babu, R. C., Boopathi, N. M., and Fukai, S. (2008). Phenotypic and genotypic analysis of drought-resistance traits for development of rice cultivars adapted to rainfed environments. Field Crops Res. 109, 1-23. doi: 10.1016/j.fcr. 2008.06.010

Kumar, A., Bernier, J., Verulkar, S., Lafitte, H. R., and Atlin, G. N. (2008). Breeding for drought tolerance: direct selection for yield, response to selection and use of drought-tolerant donors in upland and lowland-adapted populations. Field Crops Res. 107, 221-231. doi: 10.1016/j.fcr.2008.02.007

Kumar, A., Verulkar, S., Dixit, S., Chauhan, B., Bernier, J., Venuprasad, R., et al. (2009). Yield and yield-attributing traits of rice (Oryza sativa L.) under lowland drought and suitability of early vigor as a selection criterion. Field Crops Res. 114, 99-107. doi: 10.1016/j.fcr.2009.07.010

Kumar, R., Venuprasad, R., and Atlin, G. N. (2007). Genetic analysis of rainfed lowland rice drought tolerance under naturally-occurring stress in eastern India: heritability and QTL effects. Field Crops Res. 103, 42-52. doi: 10.1016/ j.fcr.2007.04.013

Lafitte, R., and Courtois, B. (2000). Genetic variation in performance under reproductive-stage water deficit in a doubled haploid rice population in upland fields. CIMMYT 2000:97.

Lanceras, J. C., Pantuwan, G., Jongdee, B., and Toojinda, T. (2004). Quantitative Trait Loci Associated with Drought Tolerance at Reproductive Stage in Rice. Plant Physiol. 135, 384-399. doi: 10.1104/pp.103.035527

Liu, H., Mei, H., Yu, X., Zou, G., Liu, G., and Luo, L. (2006). Towards improving the drought tolerance of rice in China. Plant Genet. Resour. 4, 47-53. doi: 10.1079/PGR2006111

Ndjiondjop, M. N., Manneh, B., Cissoko, M., Drame, N. K., Kakai, R. G., Bocco, R., et al. (2010). Drought resistance in an interspecific backcross population of rice (Oryza spp.) derived from the cross WAB56-104 (O. sativa) $\times$ CG14 (O. glaberrima). Plant Sci. 179, 364-373. doi: 10.1016/j.plantsci.2010. 06.006

Patterson, H. D., and Thompson, R. (1971). Recovery of Inter-Block Information when Block Sizes are Unequal. Biometrika 58, 545-554. doi: 10.2307/23 34389

Prapertchob, P., Bhandari, H., and Pandey, S. (2007). Economic costs of drought and rice farmers' drought-coping mechanisms in northeastern Thailand. Los Banos: International Rice Research Institute (IRRI).

Rao, A. N., Wani, S. P., Ramesha, M. S., and Ladha, J. K. (2017). Rice Production Systems. Cham: Springer.

Sandhu, N., and Kumar, A. (2017). Bridging the Rice Yield Gaps under Drought: QTLs, Genes, and their Use in Breeding Programs. Agronomy 7:27. doi: 10.3390/ agronomy7020027

Seyoum, M., Alamerew, S., and Bantte, K. (2012). Genetic Variability, Heritability, Correlation Coefficient and Path Analysis for Yield and Yield Related Traits in Upland Rice (Oryza sativa L.). J. Plant Sci. 7, 13-22. doi: 10.3923/jps.2012. 13.22

Solis, J., Gutierrez, A., Mangu, V., Sanchez, E., Bedre, R., Linscombe, S., et al. (2018). Genetic Mapping of Quantitative Trait Loci for Grain Yield under Drought in Rice under Controlled Greenhouse Conditions. Front. Chem. 5:129. doi: 10.3389/fchem.2017.00129

Swamy, B. P. M., Shamsudin, N. A. A., Rahman, S. N. A., Mauleon, R., Ratnam, W., Ma, T., et al. (2017). Association Mapping of Yield and Yield-related Traits Under Reproductive Stage Drought Stress in Rice (Oryza sativa L.). Rice 10:21. doi: 10.1186/s12284-017-0161-6

Venuprasad, R., Lafitte, H. R., and Atlin, G. N. (2007). Response to Direct Selection for Grain Yield under Drought Stress in Rice. Crop Sci. 47, 285-293. doi: 10.2135/cropsci2006.03.0181

Vikram, P., Swamy, B. M., Dixit, S., Ahmed, H. U., Teresa Sta, Cruz, M., et al. (2011). qDTY 1.1, a major QTL for rice grain yield under reproductive-stage drought stress with a consistent effect in multiple elite genetic backgrounds. BMC Genet. 12:89. doi: 10.1186/1471-2156-12-89

Wopereis, M. C. S., Kropff, M. J., Maligaya, A. R., and Tuong, T. P. (1996). Drought-stress responses of two lowland rice cultivars to soil water status. Field Crops Res. 46, 21-39. doi: 10.1016/0378-4290(95)00084-4

Wu, X. H., Wang, W., Yin, C. M., Hou, H. J., Xie, K. J., and Xie, X. L. (2017). Water consumption, grain yield, and water productivity in response to field water management in double rice systems in China. PLoS One 12:e0189280. doi: 10.1371/journal.pone.0189280

Xiong, W., Holman, I., Lin, E., Conway, D., Jiang, J., Xu, Y., et al. (2010). Climate change, water availability and future cereal production in China. Agricult. Ecosyst. Env. 135, 58-69. doi: 10.1016/j.agee.2009.08.015

Yan, T., Wang, J., and Huang, J. (2015). Urbanization, agricultural water use, and regional and national crop production in China. Ecol. Model. 318, 226-235. doi: 10.1016/j.ecolmodel.2014.12.021

Zeigler, R. S., and Puckridge, D. W. (1995). Improving sustainable productivity in rice-based rainfed lowland systems of South and Southeast Asia. GeoJournal 35, 307-324. doi: 10.1007/BF00989138

Conflict of Interest: The authors declare that the research was conducted in the absence of any commercial or financial relationships that could be construed as a potential conflict of interest.

Publisher's Note: All claims expressed in this article are solely those of the authors and do not necessarily represent those of their affiliated organizations, or those of the publisher, the editors and the reviewers. Any product that may be evaluated in this article, or claim that may be made by its manufacturer, is not guaranteed or endorsed by the publisher.

Copyright (c) 2022 Venkateshwarlu, Kole, Paul, Singh, Singh and Kumar. This is an open-access article distributed under the terms of the Creative Commons Attribution License (CC BY). The use, distribution or reproduction in other forums is permitted, provided the original author(s) and the copyright owner(s) are credited and that the original publication in this journal is cited, in accordance with accepted academic practice. No use, distribution or reproduction is permitted which does not comply with these terms. 